\title{
Massive Skull Base Ameloblastic Carcinoma with Intracranial Extension
}

\author{
Ali Erdem YILDIRIM¹, Denizhan DIVANLIOGLU¹, Derya KARAOGLU1', Serra KAYACETIN², Ahmed Deniz BELEN¹ \\ ${ }^{1}$ Ankara Numune Research and Education Hospital, Department of Neurosurgery, Ankara, Turkey \\ ${ }^{2}$ Ankara Numune Research and Education Hospital, Department of Pathology, Ankara, Turkey
}

\section{ABSTRACT}

Ameloblastic carcinoma $(\mathrm{AC})$ is a rare and aggressive malignant epithelial odontogenic tumor that may arise either from the mandible (66.6\%) or the maxilla (33.3\%). Besides being formed de novo, the tumor can develop from a pre-existing ameloblastoma or odontogenic cyst. The clinical course of AC is typically aggressive with extensive local destruction. AC has also been reported to spread to various parts of the body through lymphatic system. Skull base location and intracranial extension of this tumor are uncommon. In this case report we present the clinical course, management and follow up of an uncommonly large AC that destructed the anterior skull base and extended into the intracranial space.

KEYWORDS: Ameloblastic carcinoma, Skull base, Intracranial

\section{INTRODUCTION}

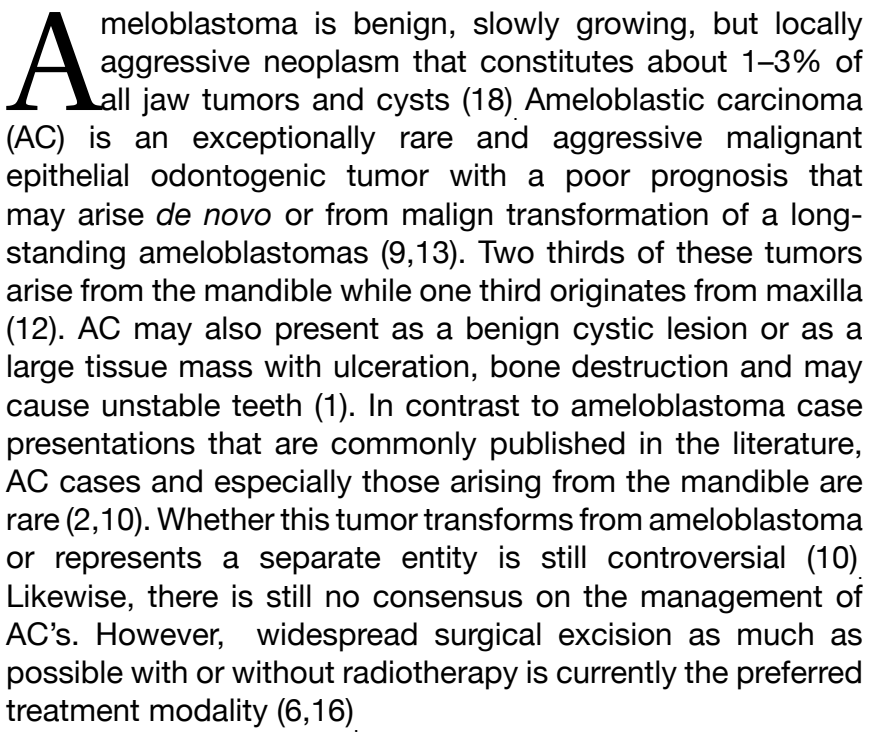

In this presentation we demonstrate the clinical course, management and follow-up of a particular case that harbored a giant $A C$ extending into the frontal lobe through destructed anterior cranial fossa. While AC's are infrequently seen in this localization, this case may contribute to the differential diagnosis of tumors in this area.

\section{CASE REPORT}

A 35-year-old male was referred to our institution with the diagnosis of an anterior cranial fossa lesion. He had been suffering consistent headache, numbness in the left half of his face, and anosmia for 3 months. There was no facial swelling or asymmetry. He did not express any pain during mastication or any difficulty in jaw movements. His symptoms had rapidly progressed in the last 3 weeks. The patient had undergone transsphenoidal biopsy elsewhere before presenting to our clinic of and the pathology result had been AC.

The patient's paranasal computed tomography (CT) scan revealed a soft tissue mass that almost completely occupied the ethmoid cells, nasal cavity, sphenoid and left maxillary 
sinuses and also destructed the lamina paprecea, clivus, and cribriform plate with intracranial extension (Figure 1). Cranial magnetic resonance imaging (MRI) displayed the lesion as a solid, lobulated mass enhancing heterogeneously with contrast that showed a similar extension pattern as seen on the CT by means of compressing both basal frontal lobes (Figure 2). A CT-angiography was performed to rule out any vascular involvement such as internal carotid arteries (ICAs) and to identify the vascularity of the tumor. On CT-angiography, the tumor was found to be considerably vascular and the ICA's did not show any displacement or involvement by the tumor. Laboratory findings including tumor markers were within the normal range.

First, we planned to approach the tumor inferiorly by aiming as much gross total resection as possible. The patient underwent

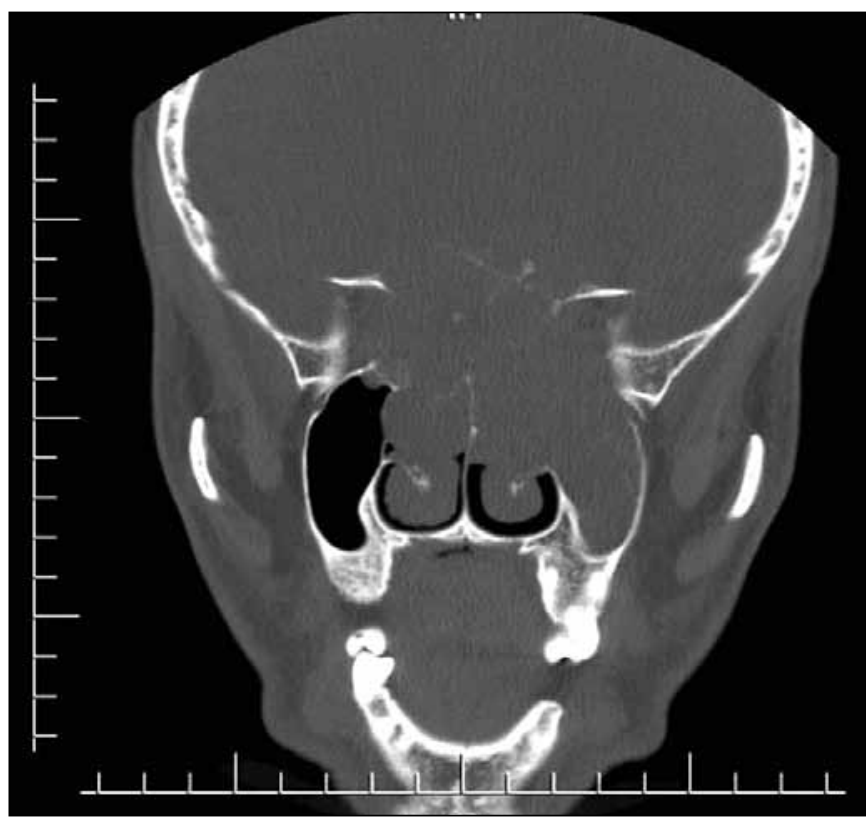

Figure 1: Preoperative coronal paranasal CT scan showing the lesion destructing anterior skull base. an extended endoscopic endonasal transsphenoidal surgery through the binostril route. The tumor was reached easily in the nasal cavity. With the help of suction/coagulation and tumor-forceps, the tumor was removed piece by piece. All tumor parts invading the nasal cavity, the maxillary sinus, the sphenoidal sinus, and the clivus were gross totally removed. Additionally, the tumor-invaded anterior cranial fossa dura mater was also excised. Although the tumor was soft in nature, its highly vascular intrastructure prevented more extensive removal and the intracranial part was left as residue. The dura mater defect was repaired with autologous graft. Postoperative early cranial MRI showed the remnant in the anterior cranial fossa (Figure 3). Histopathological examination revealed an ameloblastic carcinoma, which was consistent with the previous biopsy evaluation (Figure 4A-D). As the second step, a transcranial approach was planned on the third postoperative day for removal of the residual tumor since AC characteristically has a poor prognosis and is locally aggressive. A gross total resection with dura excision was performed through the right subfrontal approach (Figure 5). No CSF leakage or any other complications were observed after the procedures and the patient was discharged on the $4^{\text {th }}$ day after the second operation. The patient received 5000 cGy of local adjuvant radiotherapy. The patient was followed up closely and there was no recurrence at the 18-months follow-up (Figure 6).

\section{DISCUSSION}

Ameloblastic carcinomas are rare lesions. Moreover, their presentations as intracranial extension are uncommon although AC's usually show an aggressive clinical course with a poor prognosis. AC's are recognized as malignant epithelial odontogenic tumor that may occur de novo or arise from malignant transformation of a long-standing ameloblastoma $(9,13)$. Most of these tumors originate from the mandible $(2 / 3)$ and the rest from the maxilla (12). AC may also present as a benign cystic lesion or as a large tissue mass with ulceration, bone destruction and may cause unstable teeth (1).

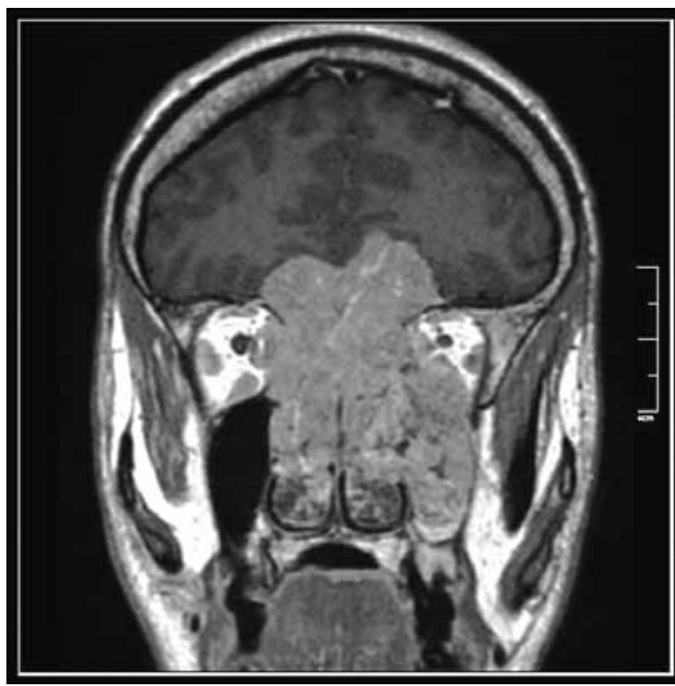

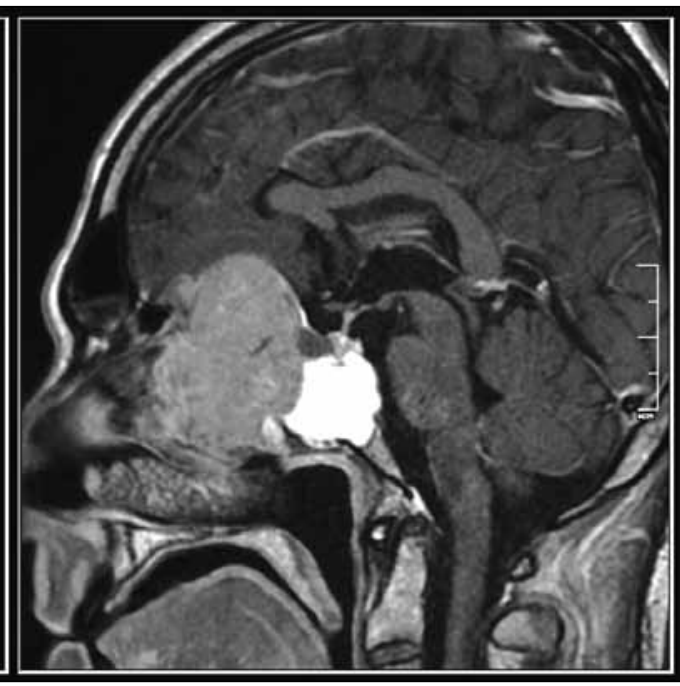

Figure 2: Preoperative coronal and sagittal enhanced cranial MRI of the patient demonstrating the huge tumor and its extensions. 


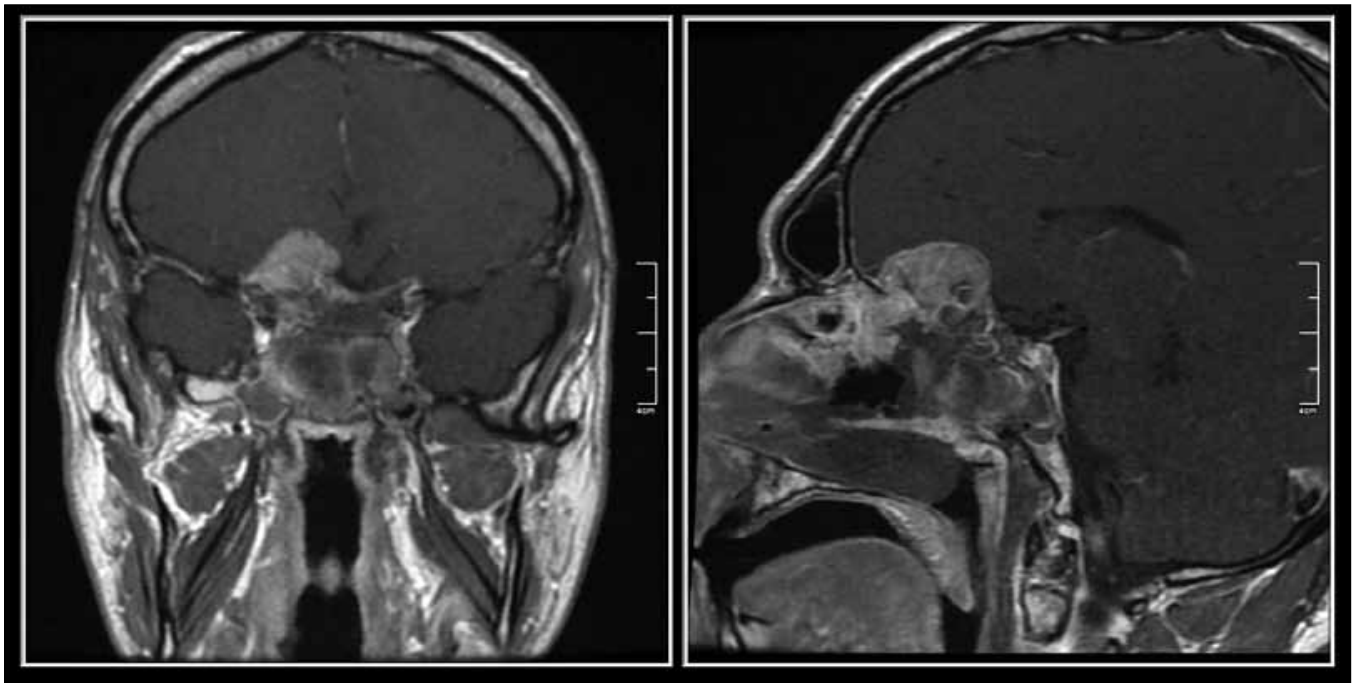

Figure 3: Coronal and sagittal enhanced cranial MRI of the patient after the first operation showing the intracranial residual tumor part.

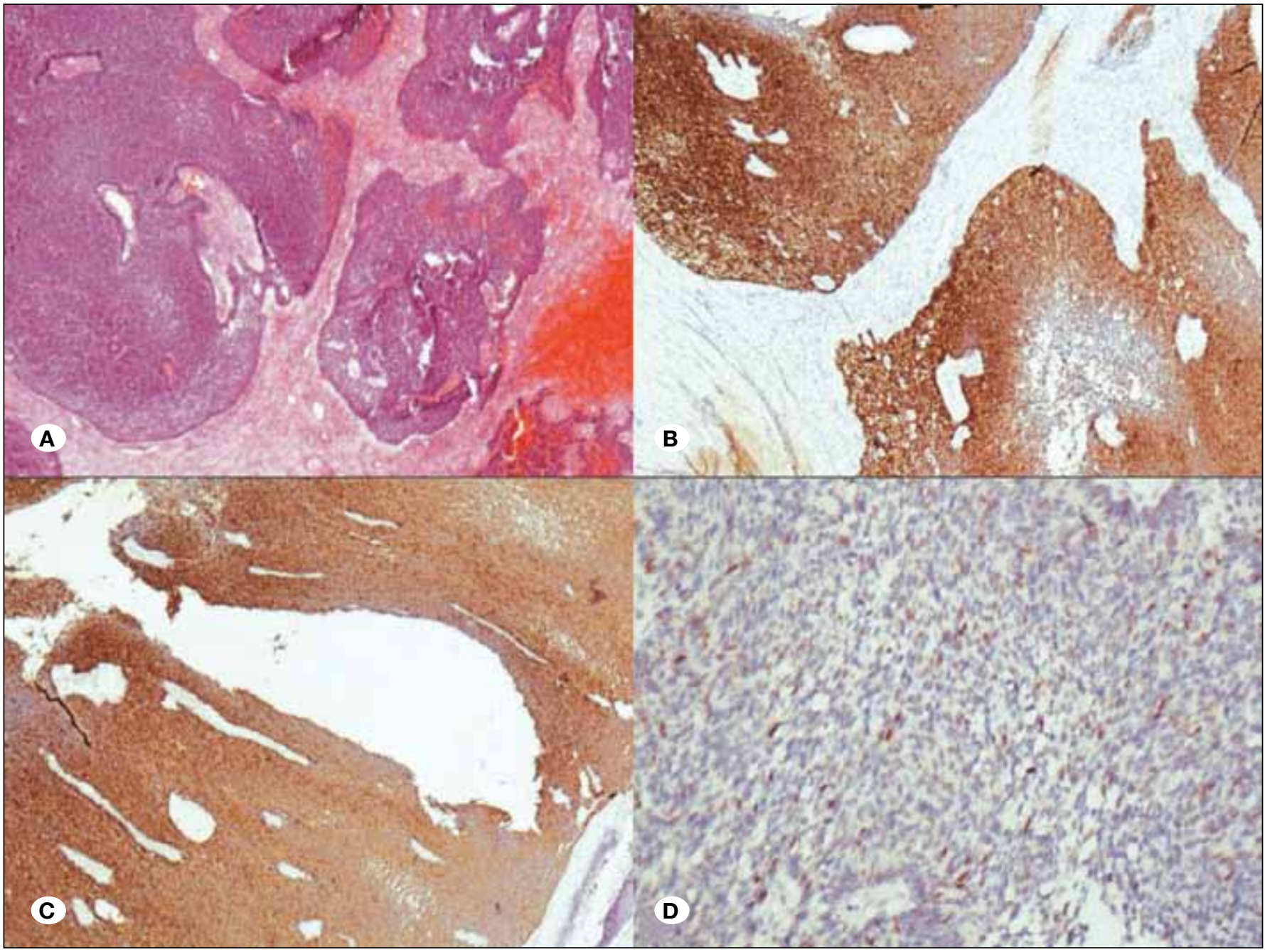

Figure 4: Photomicrograph examples of histology samples proving an ameloblastic carcinoma. Dense basaloid epithelial cells with palisading, H\&E, x40 (A). Immunohistochemical diffuse CK8 cytoplasmic staining of the cells, CK8, x40 (B). Immunohistochemical diffuse CK18 cytoplasmic staining of the cells, CK18, x40 (C). Diffuse P53 staining of the cell nuclei, P53, x200 (D). 
The histogenesis of AC's and other odontogenic tumors are poorly understood. These lesions may originate from the pluripotent cells of the basal layer of the oral and sinonasal epithelium and may also originate from ectopic teeth in the nasal cavity $(14,15,20)$. The embryological developments of the sinonasal tract and the odontogenic apparatus are closely related to each other. The oral cavity and sinonasal tract communicate with each other from the $10^{\text {th }}$ intrauterine week (12). These cavities are separated by the development of the palatine shelves. During the separation of the cavities, the odontogenic epithelium may be trapped in the sinonasal mucosa, or the sinonasal cells may acquire the capability of odontogenesis (7).

Thoma considered $\mathrm{AC}$ as a subtype of the ameloblastoma that displays malignant transformation (19). The relevant literature showed that they may occur either de novo or may arise from a pre-existing odontogenic lesion $(3,17)$. The tumors locate frequently in the posterior portion of the mandible, and maxillary involvement is less common (4) Ameloblastic carcinoma occurs in a wide range of age groups without gender predilection (4)

Ameloblastic carcinomashaveamoreaggressiveclinical course than typical ameloblastomas. Bone destructions, surrounding tissue invasions and cervical lymph node metastases can be associated with these lesions (4). Involvement of the nasal cavity usually relates to local invasion of the maxillary ACs. Destruction of the skull base and extension into the intracranial space are unusual and infrequently reported in the literature (13). In this manner, the presented case displays an illustrative example and accordingly AC's may be taken into account in the differential diagnosis of lesions located in the anterior skull base.

The management of AC's is still controversial. Surgical excision with or without adjuvant radiotherapy is the most
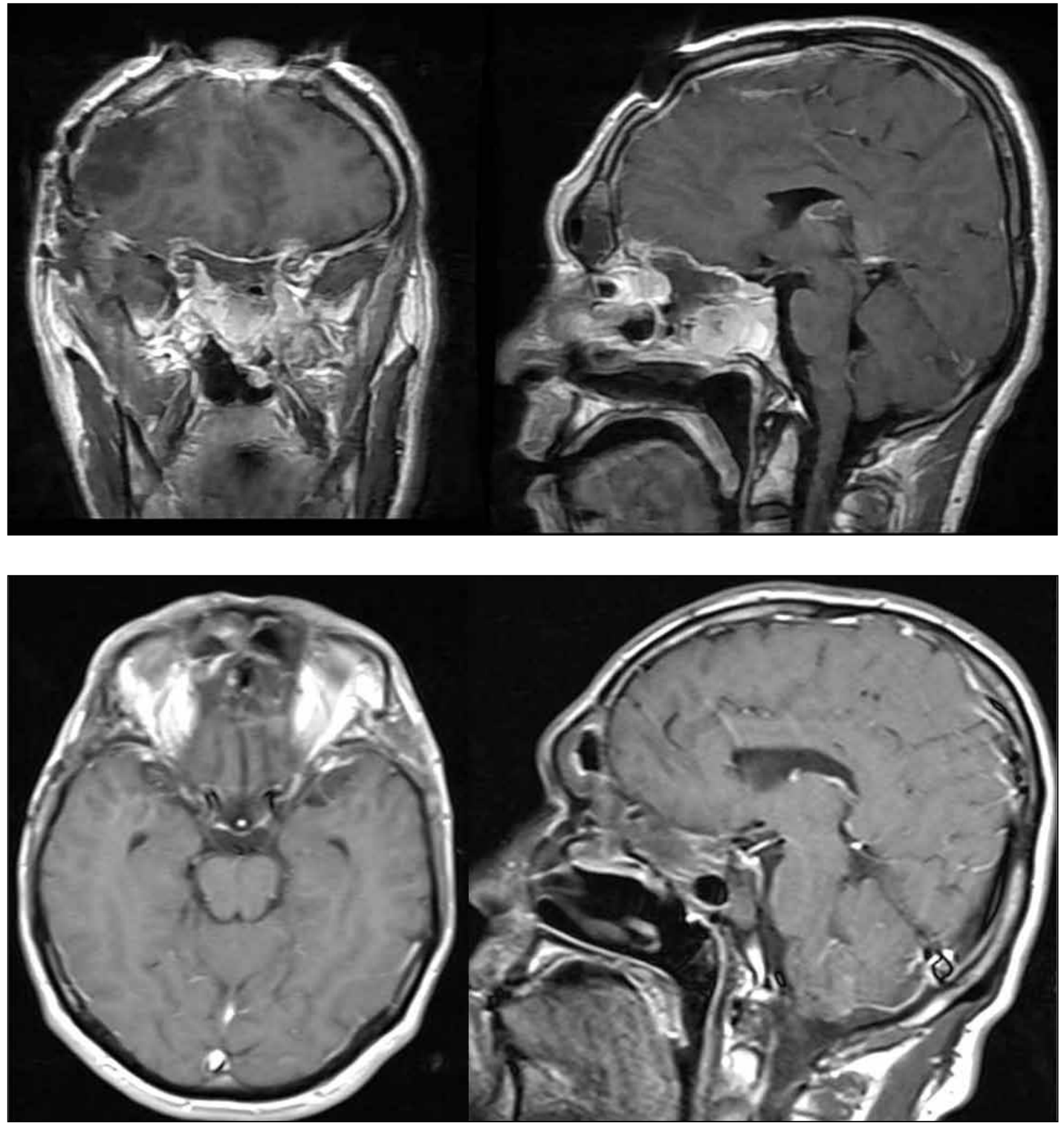

Figure 5: Coronal and sagittal enhanced cranial $\mathrm{MRI}$ of the patient after the second operation demonstrating gross total resection of the tumor with some postoperative changes inside the sphenoidal sinus.

Figure 6: Axial and sagittal enhanced cranial MRI of the patient after 18 months for operation demonstrating no tumor recurrence. 
preferable common treatment modality $(6,16)$. While most ameloblastic carcinomas are located intraosseously, the effectiveness of radiotherapy must be evaluated meticulously (10). Chemotherapy is not clearly indicated as primary treatment. En bloc removal with $1-2 \mathrm{~cm}$ of healthy bone margin is the safest surgical modality to provide disease-free survival and this resection maintains local recurrence rates of less than $15 \%$ (5). AC usually recurs locally $0.5-11$ years after final treatment. Laughlin (11) observed that the disease-free interval between the initial diagnosis and the appearance of metastases was 9 years. However, once the metastasis has occurred, the median survival period is about 2 years $(8,11)$. Due to these features of AC's, we carried out the second operation for gross total removal of the residual tumor.

\section{CONCLUSION}

$A C$ is a rare entity that has a very invasive character and can be destructive to adjacent tissues. Infrequently, the tumor may extend into the cranial space. In the management of $A C$, surgical treatment in which total or gross total removal of the tumor should be aimed has priority. Adjuvant local radiotherapy may be applied after surgery but this issue is still controversial because of inadequate knowledge. When residue or recurrence is encountered, re-operation may be considered. Patients treated for AC's must be closely followed up with repeated cranial MRI's.

\section{- REFERENCES}

1. Avon SL, McComb J, Clokie C: Ameloblastic carcinoma: Case report and literature review. J Can Dent Assoc 69: 573-576, 2003

2. Batsakis JG, McClatchey KD: Ameloblastoma of the maxilla and peripheral ameloblastomas. Ann Otol Rhinol Laryngol 92:532, 1983

3. Cizmeci O, Aslan A, Onel D, Demiryont M: Ameloblastic carcinoma ex ameloblastoma of the mandible: Case report. Otolaryngol Head Neck Surg 130: 633-634, 2004

4. Corio LR, Goldblatt LI, Edwards PA, Hartman KS: Ameloblastic carcinoma: A clinicopathologic study and assessment of eight cases. Oral Surg Oral Med Oral Pathol 64: 570-576, 1987

5. Datta R, Winston JS, Diaz-Reyes G, Loree TR, Myers L, Kuriakose MA, Riqual NR, Hicks WL Jr: Ameloblastic carcinoma: Report of an aggressive case with multiple bony metastases. Am J Otolaryngol 24: 64-69, 2003
6. Dhir K, Sciubba J, Tufano RP: Ameloblastic carcinoma of the maxilla. Oral Oncol 39: 736-741, 2003

7. Guilemany JM, Ballesteros F, Alos L, Alobid I, Prades S, Menendez LM, Cardesa A: Plexiform ameloblastoma presenting as a sinonasal tumor. Eur Arch Otorhinolaryngol 261: 304-306, 2004

8. Ingram EA, Evans ML, Zitsch RP: Fine-needle aspiration cytology of ameloblastic carcinoma of the maxilla: $A$ rare tumor. Diagn Cytopathol 14: 249-252, 1996

9. Kramer IR, Pindborg JJ, Shear M: The WHO histologica typing of odontogenic tumours: A commentary on the second edition. Cancer 70: 2988-2994, 1992

10. Kruse AL, Zwahlen RA, Gratz KW: New classification of maxillary ameloblastic carcinoma based on an evidencebased literature review over the last 60 years. Head Neck Oncol 1: 31-32, 2009

11. Laughlin EH: Metastasizing ameloblastoma. Cancer 64: 776780,1989

12. Lolachi CM, Madan SK, Jacobs JR: Ameloblastic carcinoma of the maxilla. J Laryngol Otol 109:1019-1022, 1995

13. Ozlugedik S, Ozcan M, Basturk O, Deren O, Kaptanoglu E, Adanali G, Unal A: Ameloblastic carcinoma arising from anterior skull base. Skull Base 15: 269-272, 2005

14. Ram H, Mohammad S, Husain N, Gupta PN: Ameloblastic carsinoma. J Maxillofac Oral Surg 9: 415-419, 2010

15. Schafer DR, Thompson LD, Smith BC, Wenig BM: Primary ameloblastoma of the sinonasal tract: A clinicopathologic study of 24 cases. Cancer 82: 667-674, 1998

16. Simko EJ, Brannon RB, Eibling DE: Ameloblastic carcinoma of the mandible. Head Neck 20: 654- 659, 1998

17. Slootweg PJ, Muller $\mathrm{H}$ : Malignant ameloblastoma or ameloblastic carcinoma. Oral Surg Oral Med Oral Pathol 57:168-176, 1984

18. Small IA, Waldron CA: Ameloblastoma of the jaws. Oral Surg Oral Med Oral Pathol 8: 281-297, 1955

19. Thoma KH: A textbook of oral pathology. In: Shafer WG, Hine MK, Levy BM (eds), 4th ed. Philadelphia: WB Saunders, 1983: 280-281

20. Woo SB, Smith-Williams JE, Sciubba JJ, Lipper S: Peripheral ameloblastoma of the buccal mucosa: Case report and review of the English literature. Oral Surg Oral Med Oral Pathol 63:78-84, 1987 